Cipango
Cipango

$20 \mid 2013$

Nouveaux regards sur les arts de la scène japonais I

\title{
Thierry Guthmann, Shintō et politique dans le Japon
} contemporain

Paris, L'Harmattan, 2010. 202 p.

Eddy Dufourmont

\section{OpenEdition}

\section{Journals}

Édition électronique

URL : https://journals.openedition.org/cipango/1976

DOI : $10.4000 /$ cipango.1976

ISSN : 2260-7706

Éditeur

INALCO

Édition imprimée

Date de publication : 30 octobre 2013

ISSN : 1164-5857

\section{Référence électronique}

Eddy Dufourmont, « Thierry Guthmann, Shintō et politique dans le Japon contemporain », Cipango [En ligne], 20 | 2013, mis en ligne le 18 décembre 2014, consulté le 30 juin 2021. URL : http:// journals.openedition.org/cipango/1976 ; DOI : https://doi.org/10.4000/cipango.1976

Ce document a été généré automatiquement le 30 juin 2021.

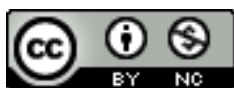

Cipango est mis à disposition selon les termes de la Licence Creative Commons Attribution - Pas d'Utilisation Commerciale 4.0 International. 


\title{
Thierry Guthmann, Shintō et politique dans le Japon contemporain
}

\author{
Paris, L'Harmattan, 2010. 202 p.
}

\section{Eddy Dufourmont}

1 À l'heure où le Japon est en friction avec la Chine à propos des îles Senkaku et connaît une vague de discours populistes et révisionnistes, l'analyse que propose Thierry Guthmann, politologue à l'université de Mie (Japon), sur le shintō et la politique dans le Japon contemporain est bienvenue pour pallier le manque d'ouvrages francophones sur la question.

2 L'auteur justifie son ouvrage en partant du constat de l'intérêt exclusif de la recherche pour le bouddhisme dans la question du rapport entre religion et politique au Japon, au détriment du shintō. Or, considérer le shintō est d'autant plus important aux yeux de l'auteur que le Japon moderne a fait l'expérience d'un shintō d'État, dont l'idéologie fait un retour en force à partir des années 1960, en parallèle avec une remise en cause du pacifisme constitutionnel. À partir de là, l'auteur se propose d'étudier concrètement la relation religion/politique à travers les rapports entre le monde politique et la «Ligue policito-shintoïste " (Shintō seiji renmei), principal représentant des sanctuaires shintō selon lui. Mais d'emblée le champ d'intérêt de l'auteur va bien au-delà du Japon : il entend en effet rapprocher le cas japonais de celui des « démocraties occidentales », en abordant les cas français et américain, afin d'élaborer un modèle des relations religion/ politique dans les démocraties contemporaines. L'auteur justifie le choix de ces deux pays parce qu'ils sont tous deux aux extrémités en matière religieuse : les États-Unis étant considérés comme les plus religieux, la France le moins.

3 L'ouvrage se divise en cinq chapitres, qui constituent deux étapes différentes de la réflexion de l'auteur : les trois premiers chapitres sont consacrés à la « Ligue politicoshintoïste ", les deux suivants à un rappel des relations entre religion et politique en France et aux États-Unis, qui permet une réflexion sur un modèle rendant compte des relations entre religion et politique dans les démocraties européennes. S'appuyant sur les revues actuelles publiées par la "Ligue politico-shintoïste", l'auteur rend bien compte des idées de l'organisation sur le plan politique, qui sont celles des 
conservateurs les plus nationalistes. Sur le plan des relations de la Ligue avec le monde politique, l'auteur s'attarde sur les discours de Mori Yoshirō et une mise en évidence des liens personnels entre des membres du PLD, à commencer par Abe Shinzō, et la Ligue. Dans le troisième temps, sur la question de l'environnement idéologique de la société japonaise contemporaine, l'auteur rend compte des différents sondages pratiqués au Japon au sujet des points qui constituent les revendications de la Ligue. L'auteur montre bien l'écart plutôt important entre les aspirations que la Ligue a pour le Japon et les attentes des citoyens, avec des exceptions notables en ce qui concerne les questions de défense, de réforme de l'article 9 , et des visites officielles au sanctuaire Yasukuni. On peut y trouver une clé pour comprendre le retour d'Abe Shinzō au poste de Premier ministre.

4 Thierry Guthmann dresse ainsi un tableau intéressant de la place du shintō dans le fait politique des années 2000, un tableau d'autant plus bienvenu que le monde francophone manque d'ouvrages sur la politique japonaise. Si l'apport est indéniable, son travail ne saurait pourtant à lui seul traiter de façon complète du shintō et de la politique dans le Japon contemporain - contrairement à ce que le titre semble suggérer - et surtout, la démarche peut d'une manière générale prêter à plusieurs interrogations.

5 Le point de départ de l'auteur est le constat que les recherches sur les relations entre religions et politique au Japon se sont concentrées avant tout sur le bouddhisme avec le Kōmeitō. S'il est vrai que ce parti, émanation de la Sōka gakkai, a fait l'objet de nombreux travaux, ce constat doit être nuancé. Il existe des travaux sur la place du shintō dans la politique japonaise, ce qui n'est guère étonnant au vu de l'importance de celui-ci au Japon : Shimazono Susumu est le principal contributeur en la matière.

Le portrait du shintō que pose Thierry Guthmann peut lui aussi prêter à interrogation. Il le décrit comme un ensemble de croyances de "type animiste", un terme suranné. Surtout, il le présente comme la religion de l'« écrasante majorité des Japonais ». Est-on sûr que la pratique religieuse des Japonais d'aujourd'hui suit ce schéma? Il y a là un risque d'essentialisation tout aussi grand que de parler de «croyances monothéistes occidentales». Par ailleurs, l'auteur suggère que la «Ligue politico-shintoïste» représente le shintō. Certes il entend étudier la dimension religieuse du fait politique et non la dimension politique du fait religieux, mais n'y a-t-il pas là aussi un risque, celui d'accorder trop d'importance à cette organisation, et surtout d'abonder dans son sens en la présentant comme la représentante de cette religion? En d'autres termes, l'auteur devrait s'interroger sur les liens entre cette organisation et les fidèles du shintō, car il est possible que cette organisation n'ait pas l'audience que l'on veut bien croire.

7 En traitant de la "Ligue policito-shintoïste», Thierry Guthmann adopte essentiellement une démarche de politologue et s'intéresse au Japon des années 2000. On peut ici regretter l'absence d'une perspective historique. L'auteur aurait alors vu, comme nous l'avons nous-même fait dans des travaux précédant son ouvrage, que les liens entre l'organisation et une partie des conservateurs sont anciens et ont évolué. Si la question de la révision de la Constitution et du retour aux symboles du régime impérial faisait consensus chez les conservateurs dans les années 1950, les années passant, ces idées se sont progressivement limitées à l'aile droite du PLD, proche de Fukuda Takeo. Or c'est à cette aile que la Ligue a toujours été rattachée. Si le nationalisme chanté par cette aile et la Ligue représente surtout les élites sur le plan 
social (comme le montre par exemple la Soshinkai), le nationalisme actuel a une dimension beaucoup plus populaire, et il reste à savoir à quel point la Ligue y possède de l'audience. Les personnalités du PLD liées à la Ligue sont bien présentées pour leur discours, mais une enquête sur leurs familles et leurs parcours apporterait également d'autres éclaircissements. De même, les liens avec la pègre et les organisations d'extrême droite mériteraient d'être étudiés.

8 La partie consacrée au rapport religion-politique en France et aux États-Unis est peutêtre la moins convaincante : plutôt que d'instaurer un dialogue avec des spécialistes de ces pays, l'auteur a préféré développer une réflexion personnelle à partir de ses lectures, avec le risque d'ignorer des travaux importants. Abordant la question du rapport religion-politique, l'auteur se confrontait nécessairement à la question de la laïcité : non seulement ce mot est quasiment absent de son ouvrage, mais des recherches qui font autorité en la matière sont ignorées. On ne peut que le regretter.

9 Au final, si l'ouvrage apporte des éclairages indéniables, il ne peut répondre à lui seul au champ d'interrogations qu'il pose, et de ce fait constitue une amorce de recherches qui - on l'espère - se poursuivront.

\section{AUTEUR}

\section{EDDY DUFOURMONT}

Université de Bordeaux III 